\title{
Safety and Feasibility of Single-port Surgery for Colon Cancer in Octogenarians
}

\author{
MITSUYOSHI TEI, MASAHISA OTSUKA, YOZO SUZUKI, KENTARO KISHI, \\ MASAHIRO TANEMURA and HIROKI AKAMATSU
}

Department of Surgery, Osaka Police Hospital, Osaka, Japan

\begin{abstract}
Background/Aim: The use of single-port surgery (SPS) in elderly patients with colon cancer remains controversial. The aim of this study was to evaluate the clinical outcomes of elderly patients who underwent SPS. Patients and Methods: Consecutive patients $>80$ years old of age who underwent SPS $(n=86)$ or multi-port surgery (MPS) ( $n=40)$ for colon cancer from January 2008 to December 2014 were analyzed. Short-term and long-term outcomes were compared between groups. Results: The morbidity rate in the SPS was significantly lower than that in the MPS ( $p=0.027)$. Length of hospital stay in the SPS was significantly shorter than that in the MPS $(p=0.016)$. Similar oncological outcomes were observed in the groups. The 3-year disease-free survival rate, the 5-year overall survival rate and the 5-year cancer-specific survival rate did not differ significantly between groups. Conclusion: SPS is safe and can provide clinical outcomes comparable to those of MPS in octogenarians with colon cancer.
\end{abstract}

Recently, the number of surgeries for elderly patients with colorectal cancer has been increasing in Japan. Surgery is the most effective treatment for colorectal cancer, but tends to be associated with higher morbidity and mortality rates in elderly compared to younger patients. Several studies have shown that laparoscopic surgery is superior to open surgery in terms of postoperative outcomes, including reduction of pain, earlier intestinal peristaltic recovery, shortening of postoperative stay, and cosmetic advantage (1-7), and can provide long-term oncological outcomes comparable to those of open surgery in elderly patients with colorectal cancer (8). The frequency of laparoscopic surgery for colorectal cancer

Correspondence to: Mitsuyoshi Tei, MD, Ph.D., Department of Surgery, Osaka Police Hospital 10-31, Kitayama-cho, Tennoji-ku, Osaka City, Osaka, 543-0035, Japan. Tel: +81 667716051, Fax: +81 667752838, e-mail: mtei@live.jp

Key Words: Single-incision laparoscopic surgery, single-port surgery, elderly, octogenarians, colon cancer. was $46.8 \%$ in 2011 according to the 11th Nationwide Survey of Endoscopic Surgery in Japan (9), and it is expected that the number of patients who undergo laparoscopic surgery will increase in the future.

Single-port surgery (SPS) is a recent advance in minimally invasive techniques. The first SPS was described for right colectomy in 2008 (10), and the benefits included better cosmetic outcomes, less postoperative pain, faster postoperative recovery, and earlier hospital discharge (1113). Additionally, several reports have found that SPS is feasible and safe for colorectal cancer in terms of short-term and long-term oncological outcomes (14-18).

Less invasive procedures for colorectal cancer surgery are becoming increasingly popular because they achieve better short-term postoperative results. However, the effect of less invasive surgery in elderly patients with colon cancer is unknown. Therefore, the aim of this study was to evaluate the clinical outcomes of SPS in elderly patients with colon cancer and to compare these outcomes with those of patients with colon cancer who underwent multi-port surgery (MPS).

\section{Materials and Methods}

Patient profiles. In our Department, the first case of SPS for colon cancer was carried out in May, 2009. Before April 2012, SPS was performed only for early colon cancer, but the indication was expanded gradually to include advanced colorectal cancer. Currently, SPS is considered a reasonable alternative approach for colon cancer in our department. Exclusion criteria were obstruction or perforation that required emergent surgery, massive invasion of cancer into adjacent organs that could not be resected laparoscopically, and withdrawal of informed consent. Patients received written information describing the differences between SPS and MPS. In addition, they received a thorough explanation of each operative procedure. All of the patients agreed to receive SPS and to provide written informed consent.

Between January 2008 and December 2014, a total of 182 consecutive patients $>80$ years of age underwent colectomy for colon carcinoma. Of these, 19 patients had a diagnosis of Stage IV disease. Of these, 19 patients underwent emergency surgery. Of these, 18 patients underwent open surgery. In total, our series was composed of 86 patients who underwent SPS and 40 who underwent MPS (Figure 1). 
Age, gender, tumor location, body mass index (BMI), American Society of Anesthesiologists (ASA) score, performance status (PS), Charlson risk index (19), comorbidities, management of preoperative anticoagulation, past history of previous abdominal surgery, operative procedure, stoma creation, operative time, blood loss, extent of lymph node dissection, conversion to open surgery, postoperative complications, oncologic resection, histopathological TNM staging, and long-term outcomes were obtained from the medical records. The extent of lymph node dissection was defined by the Japanese Classification of Colorectal Carcinoma (20). Postoperative complications were classified according to the Clavien-Dindo Classification (21). Operative mortality was defined as death on the same admission or within 30 days of surgery. All patients were followed for at least 30 days after surgery.

Statistical methods. Continuous data are expressed as median (range), unless specifically noted. Statistical analyses were performed with the JMP 11.0 software (SAS Institute Inc., Cary, NC). All group data were reported as median values. Differences in age, BMI, operative time, blood loss, length of hospital stay, tumor size and number of harvested lymph nodes were analyzed by MannWhitney's $U$-test. Other variables were analyzed by Fischer's exact probability test. The disease-free survival, overall survival and cancer-specific survival were determined with Kaplan-Meier analysis with a log-rank test. Statistical significance was established at $p<0.05$.

\section{Results}

Data from 126 patients (51 males and 75 females) > 80 years of age who underwent laparoscopic surgery for colon cancer at our department were analyzed. Table I lists the patient profiles analyzed in both groups. The number of patients with management of perioperative anticoagulation was significantly higher in the SPS group than in the MPS group $(p=0.006)$. The other factors did not differ significantly between groups (Table I).

Table II shows the operative details of the two groups. There were no significant differences between groups in terms of operative procedure, the rate of stoma creation, operative time, blood loss and extent of lymph node dissection. Two patients who underwent right hemicolectomy in the SPS group required an additional port. One patient who underwent sigmoidectomy in the MPS group was converted to open surgery. The reason was difficulty of development of an operative field due to a severe adhesion. None of the patients in either group had intraoperative complications (Table II).

Table III summarizes the postoperative complications that occurred in each group. Anastomotic leakage occurred in 1 patient who underwent right hemicolectomy in the SPS group. The incidence of postoperative delirium was significantly lower in the SPS group than in the MPS group (SPS, $\mathrm{n}=12,14.0 \%$ vs. MPS, $\mathrm{n}=14,35.0 \%, p=0.009$ ). Reoperation was performed in two patients in each group

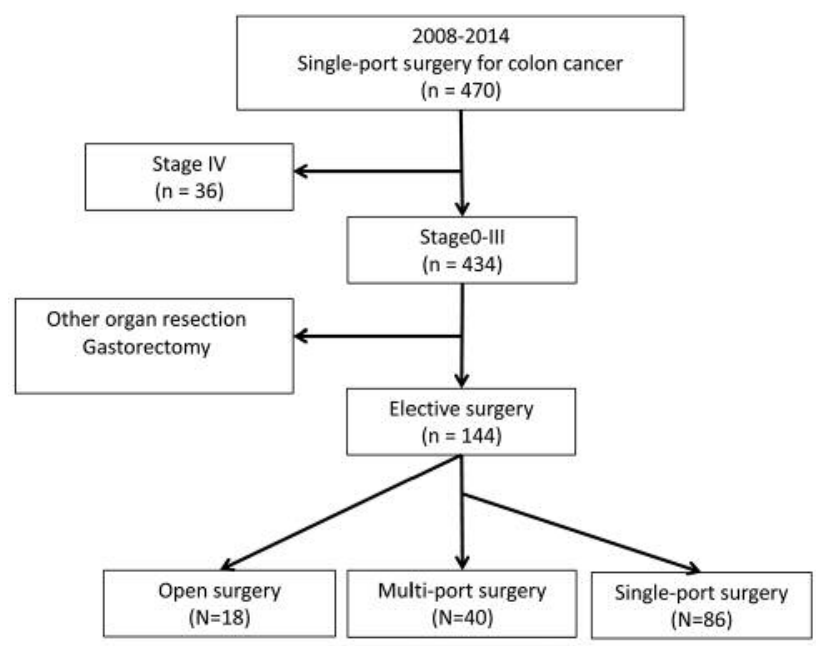

Figure 1. Flowchart of SPS and MPS in elderly patients with colon cancer.

$(p=0.591)$. Four of the patients in the MPS group experienced perioperative death (pneumoniae in two and disseminated intravascular coagulation in two). The overall postoperative complication rate was significantly lower in the SPS group than in the MPS group (SPS, $\mathrm{n}=26,30.2 \% \mathrm{vs}$. MPS, $\mathrm{n}=20,50.0 \%, p=0.027)$. The incidence of bleeding, wound infection, abdominal abscess, pneumonia, and bowel obstruction did not differ significantly between groups. The median length of hospital stay was significantly shorter in the SPS group than that in the MPS group ( 9 vs. 10 days, respectively; $p=0.016$ ). Hospital readmission within 30 days after surgery occurred for one patient in the SPS group. An 86-year-old man who had undergone a SPS transverse colectomy experienced a diverticulum bleeding of the right colon and required vascular embolization on postoperative day 14 (Table III).

Table IV summarizes the oncological resection and pathological features of the two groups. The median tumor size did not differ between groups (40 $\mathrm{mm}$ in the SPS group vs. $47 \mathrm{~mm}$ in the MPS group, respectively $p=0.208$ ). The median number of harvested lymph nodes was similar in both groups (22vs. 27, respectively $p=0.060$ ). There were no significant differences between groups in terms of tumor differentiation, depth of tumor invasion and lymph node metastasis (Table IV).

Table $\mathrm{V}$ lists the details of TNM stage and cancer recurrence in both groups. TNM stage, adjuvant chemotherapy and recurrence rate did not differ significantly between groups. The median follow-up period was 49 (range=7-70 months) months in the SPS group and 61 (range $=1-77$ months) months in the MPS group $(p<0.001)$. This difference was expected, because almost all MPS cases 
Table I. Patient demographics.

\begin{tabular}{|c|c|c|c|}
\hline & $\begin{array}{l}\text { SPS group } \\
\quad(\mathrm{n}=86)\end{array}$ & $\begin{array}{l}\text { MPS group } \\
\quad(\mathrm{n}=40)\end{array}$ & $p$-Value \\
\hline Age (years) & $83(80-93)$ & $84(80-93)$ & 0.213 \\
\hline Gender, n (\%) & & & 0.560 \\
\hline Male & $33(38.4)$ & $18(45.0)$ & \\
\hline Female & $53(61.6)$ & $22(55.0)$ & \\
\hline Tumor location, $\mathrm{n}(\%)$ & & & 0.444 \\
\hline Right colon & $47(54.7)$ & $25(62.5)$ & \\
\hline Left colon & $39(45.3)$ & $15(37.5)$ & \\
\hline BMI & $22.1(15.4-31.2)$ & $20.6(12.8-39.9)$ & 0.052 \\
\hline ASA score, $\mathrm{n}(\%)$ & & & 0.554 \\
\hline 1 or 2 & $52(60.5)$ & $27(67.5)$ & \\
\hline$\geq 3$ & $34(39.5)$ & $13(32.5)$ & \\
\hline Performance status, n (\%) & & & 0.585 \\
\hline 0 or 1 & $75(87.2)$ & $33(82.5)$ & \\
\hline$\geq 2$ & $11(12.8)$ & $7(17.5)$ & \\
\hline Charlson risk index & & & 0.826 \\
\hline $3<$ & $64(74.4)$ & $31(77.5)$ & \\
\hline$\geq 3$ & $22(25.6)$ & $9(22.5)$ & \\
\hline \multicolumn{4}{|l|}{ Comorbidities, n (\%) } \\
\hline Cerebrovascular disease* & $15(17.4)$ & $9(22.5)$ & 0.626 \\
\hline Cardiac disease* & $33(38.4)$ & $12(30.0)$ & 0.427 \\
\hline Pulmonary disease* & $13(15.1)$ & $2(5.0)$ & 0.142 \\
\hline Diabetes & $12(14.0)$ & $9(22.5)$ & 0.304 \\
\hline $\begin{array}{l}\text { Management of } \\
\text { perioperative } \\
\text { anticoagulation, n (\%) }\end{array}$ & $31(36.0)$ & $5(12.5)$ & 0.006 \\
\hline $\begin{array}{l}\text { Previous abdominal } \\
\text { surgery, } \mathrm{n}(\%)\end{array}$ & $31(36.0)$ & $10(25.0)$ & 0.307 \\
\hline
\end{tabular}

Data are number of patients and (percentage). ASA score: American Society of Anesthesiology Score; BMI: body mass index; SPS: singleport surgery; MPS: multi-port surgery. *Cerebrovascular disease: history of transient ischemic attacks and cerebrovascular event with or without neurological deficit; *Cardiac disease: ischemic disease, chronic heart failure and cardiomyopathy, excluded hypertension; *Pulmonary disease: asthma, chronic obstructive pulmonary disease, and interstitial pneumonia.

predated those in the SPS group. In the SPS group, nine patients had distant metastases (liver, $\mathrm{n}=4$, lung, $\mathrm{n}=3$, distant lymph node, $n=2$, and peritoneum, $n=2$ ). In the MPS group, six patients had distant metastases (liver, $\mathrm{n}=1$, lung, $\mathrm{n}=1$, distant lymph node, $\mathrm{n}=3$, and peritoneum, $\mathrm{n}=3$ ) (Table V). The disease-free survival rate at 3 years did not differ significantly between groups $(89.3 \%$ in the SPS group vs. $85.7 \%$ in the MPS group, $p=0.433$ ) (Figure 2). The overall survival rate at 5 years did not differ significantly between groups $(77.5 \%$ in the SPS group vs. $60.9 \%$ in the MPS group, $p=0.126$ ) (Figure 3 ). The cancer-specific survival rate at 5 years did not differ significantly between groups $(89.6 \%$ in the SPS group $v s .82 .7 \%$ in the MPS group, $p=0.405$ ) (Figure 4).
Table II. Operative detail.

\begin{tabular}{|c|c|c|c|}
\hline & $\begin{array}{l}\text { SPS group } \\
\quad(\mathrm{n}=86)\end{array}$ & $\begin{array}{l}\text { MPS group } \\
\quad(\mathrm{n}=40)\end{array}$ & $p$-Value \\
\hline Operative procedure, $\mathrm{n}(\%)$ & & & 0.472 \\
\hline Ileocecal resection & $31(5.5)$ & $13(18.5)$ & \\
\hline Right hemicolectomy & $16(17.8)$ & $12(20.2)$ & \\
\hline Left hemicolectomy & $2(17.3)$ & $1(9.2)$ & \\
\hline Sigmoidectomy & $27(3.4)$ & $8(27.7)$ & \\
\hline High anterior resection & $10(35.2)$ & $6(16.8)$ & \\
\hline Stoma creation, n (\%) & $3(3.5)$ & $1(2.5)$ & 1.000 \\
\hline $\begin{array}{l}\text { Median operative time, } \\
\text { min (range) }\end{array}$ & $176(80-488)$ & $183(101-480)$ & 0.155 \\
\hline $\begin{array}{l}\text { Median blood loss, } \\
\text { ml (range) }\end{array}$ & $5(5-560)$ & $5(5-650)$ & 0.887 \\
\hline $\begin{array}{l}\text { Extent of lymph node } \\
\text { dissection, } \mathrm{n}(\%)\end{array}$ & & 0.838 & \\
\hline D2 & $26(31.5)$ & $13(30.5)$ & \\
\hline D3 & $60(68.5)$ & $27(69.5)$ & \\
\hline $\begin{array}{l}\text { Conversion to open } \\
\text { surgery, } \mathrm{n}(\%)\end{array}$ & 0 & 1 & - \\
\hline $\begin{array}{l}\text { Required additional } \\
\text { port, } \mathrm{n}(\%)\end{array}$ & 2 & 0 & - \\
\hline
\end{tabular}

SPS: Single-port surgery; MPS: multi-port surgery.

Table III. Postoperative complications.

\begin{tabular}{lccc}
\hline Complication, $\mathrm{n}(\%)$ & $\begin{array}{c}\text { SPS group } \\
(\mathrm{n}=86)\end{array}$ & $\begin{array}{c}\text { MPS group } \\
(\mathrm{n}=40)\end{array}$ & $p$-Value \\
\hline Bleeding & 0 & $1(2.5)$ & 0.316 \\
Anastomotic leakage & $1(1.2)$ & 0 & 1.000 \\
Wound infection & $8(9.3)$ & $3(7.5)$ & 1.000 \\
Abdominal abscess & $5(5.8)$ & $3(7.5)$ & 0.708 \\
Pneumonia & $2(2.4)$ & $4(10.0)$ & 0.080 \\
Bowel obstruction & $6(7.0)$ & $4(10.0)$ & 0.724 \\
Postoperative delirium & $12(14.0)$ & $14(35.0)$ & 0.009 \\
Perioperative death & 0 & $4(10.0)$ & 0.001 \\
Reoperation & $2(2.4)$ & $2(5.0)$ & 0.591 \\
Overall complication & $26(13.4)$ & $20(50.0)$ & 0.027 \\
Length of hospital stay, & & & \\
$\quad$ days (range) & $9(7-64)$ & $10(7-68)$ & 0.016 \\
Readmission within 30 days & $1(0.5)$ & 0 & 1.000 \\
\hline
\end{tabular}

SPS: Single-port surgery; MPS: multi-port surgery.

\section{Discussion}

Based on our previous experience, we reported that SPS for colon cancer is similar to MPS in terms of short-term surgical results and oncological clearance $(18,22)$, and in addition, we believe that SPS is superior in terms of port-site related complications, cosmetic advantage and patient satisfaction. In our study, SPS was performed successfully 
Table IV. Oncological resection and pathological features.

\begin{tabular}{lccc}
\hline & $\begin{array}{c}\text { SPS group } \\
(\mathrm{n}=86)\end{array}$ & $\begin{array}{c}\text { MPS group } \\
(\mathrm{n}=40)\end{array}$ & $p$-Value \\
\hline $\begin{array}{l}\text { Tumor size, mm (range) } \\
\text { Median number of harvested }\end{array}$ & $40(8-140)$ & $45(7-100)$ & 0.208 \\
$\begin{array}{l}\text { lymph nodes (range) } \\
\text { Tumor differentiation, } \mathrm{n}(\%)\end{array}$ & $22(4-54)$ & $27(5-71)$ & 0.060 \\
$\quad$ Well & $23(26.7)$ & $6(15.0)$ & \\
$\quad$ Moderate & $50(58.1)$ & $26(65.0)$ & \\
Poor & $4(4.7)$ & $4(10.0)$ & \\
Mutinous & $7(8.1)$ & $3(7.5)$ & \\
Sig & $2(2.3)$ & $1(2.5)$ & \\
Depth of tumor invasion, $\mathrm{n}(\%)$ & & & 0.196 \\
T1 & $17(19.8)$ & $5(12.5)$ & \\
T2 & $6(7.0)$ & $2(5.0)$ & \\
T3 & $48(55.8)$ & $19(47.5)$ & \\
T4 & $15(19.8)$ & $14(35.0)$ & 0.843 \\
Lymph node metastasis, $\mathrm{n}(\%)$ & & & \\
Negative & $56(65.1)$ & $25(62.5)$ & \\
Positive & $30(34.9)$ & $15(37.5)$ & \\
\hline
\end{tabular}

SPS: Single-port surgery; MPS: multi-port surgery; Well: wel differentiated adenocarcinoma; Moderate: moderate differentiated adenocarcinoma; Poor: poorly differentiated adenocarcinoma; Mutinous: mutinous adenocarcinoma; Sig: signet ring cell carcinoma.

Table V. TNM stage and recurrence.

\begin{tabular}{lccc}
\hline & $\begin{array}{c}\text { SPS group } \\
(\mathrm{n}=86)\end{array}$ & $\begin{array}{c}\text { MPS group } \\
(\mathrm{n}=40)\end{array}$ & $p$-Value \\
\hline TNM stage, n (\%) & & & 0.309 \\
$\quad$ I & $19(22.1)$ & $6(15.0)$ & \\
II & $37(43.0)$ & $19(47.5)$ & \\
III & $30(34.9)$ & $15(37.5)$ & \\
Adjuvant chemotherapy & & & 0.645 \\
(stage III), n (\%) & & & \\
$\quad$ Yes & $4(13.3)$ & $1(6.7)$ & \\
$\quad$ No & $26(82.7)$ & $14(93.3)$ & \\
Median follow-up time, & & & \\
month, (range) & $49(7-70)$ & $61(1-77)$ & $<0.001$ \\
Recurrence, n (\%) & & & \\
Liver & $4(4.7)$ & $1(2.5)$ & \\
Lung & $3(3.5)$ & $1(2.5)$ & \\
Distant lymph nodes & $2(2.3)$ & $3(7.5)$ & \\
Peritoneum & $2(2.3)$ & $3(7.5)$ & \\
\hline
\end{tabular}

SPS: Single-port surgery; MPS: multi-port surgery.

in $97.8 \%$ of patients, including 31 patients who had a history of previous abdominal surgery. Previous studies have reported that the operative time for SPS ranged from 135 to 178 minutes $(12,14-18)$, and the conversion rate from MPS to open surgery ranged from 1.5 to $10.9 \%(12,14-18)$. In this

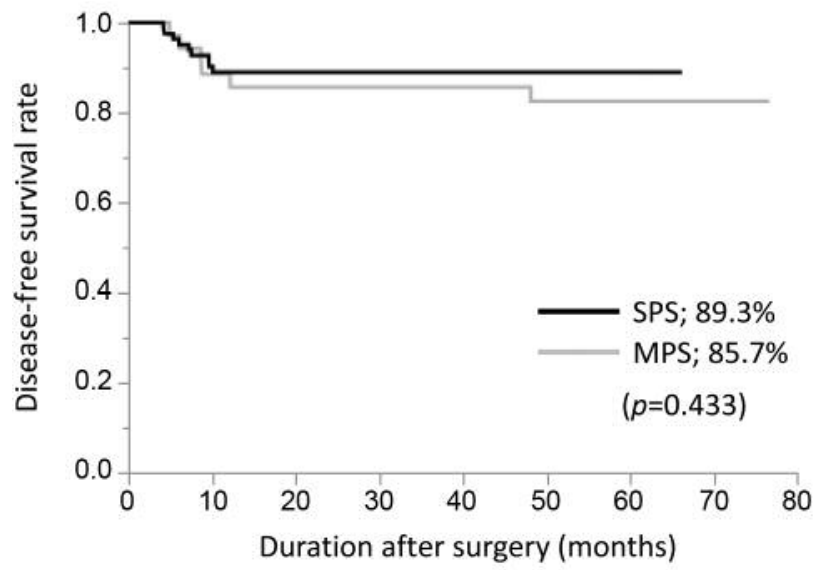

Figure 2. Kaplan-Meier analysis of disease-free survival at 3 years in the SPS and MPS group.

study, almost all MPS cases predated those in the SPS group. Additionally, we have experienced 800 single-port laparoscopic colorectal surgeries to date. Though this study analyzed 126 consecutive patients retrospectively, our results with SPS had high reliability in terms of operative time, blood loss, extent of lymph node dissection and a successful completion rate for colon cancer in elderly patients.

Also, the overall postoperative complication rate was significantly lower in the SPS group than in the MPS group ( $13.4 \%$ vs. $50.0 \%$, respectively; $p=0.027$ ). In particular, the incidence of postoperative delirium was significantly lower in the SPS group than in the MPS group (14.0 vs. 35.0\%, respectively, $p=0.009)$. We have reported that the risk of postoperative delirium is associated with operative approach (23).Operation-specific risk factors for the development of postoperative delirium are based on the degree of operative stress. Although it is controversial whether SPS is less invasive than MPS in elderly patients, we believe that the degree of operative stress with SPS is less than that with MPS. In this study, the overall postoperative complication rate in the MPS group was higher compared with other reports (14-17). In our study, minor complications that might have little or no influence on the length of hospital stay were counted. Nevertheless, the complication rate is within an acceptable range. The median length of hospital stay in the SPS group was shorter than that in the MPS group ( 9 vs. 10 days, respectively; $p=0.016$ ). Regarding the length of hospital stay, recent studies in Western countries indicate a median or mean postoperative hospital stay of 6 to 8 days (24-26), whereas the median hospital stay was 9 days in the SPS group and 10 days in the MPS group in this study. The reason for the longer hospital stay in Japan is that the Japanese health insurance system, maintains low medical costs, and has influenced this result. 


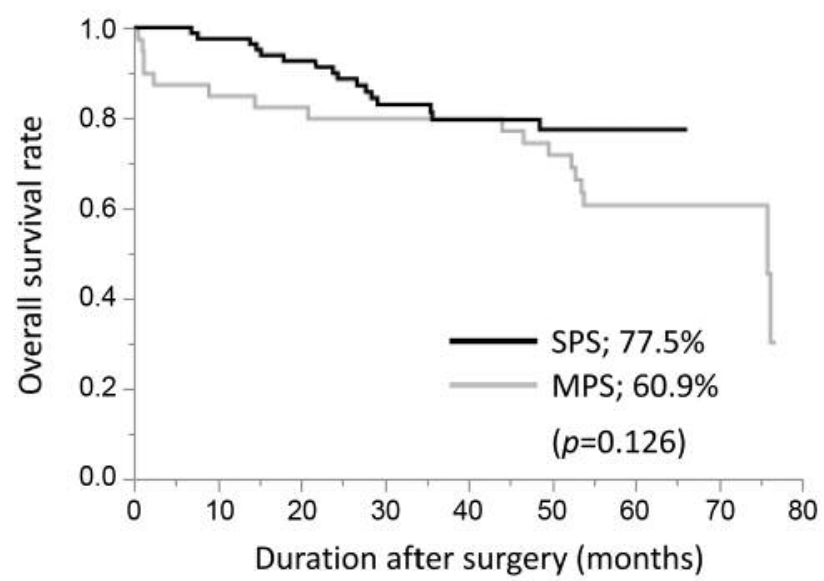

Figure 3. Kaplan-Meier analysis of overall survival at 5 years in the SPS and MPS group.

Maintenance of the surgical oncologic safety is the most important factor. High vascular ligation and a non-touch technique were maintained in this series. No gross or microscopic positive resection margins were observed in either group. In this study, the 3-year disease-free survival rate did not differ significantly between groups $(89.3 \%$ in the SPS group vs. $85.7 \%$ in the MPS group, $p=0.433$ ). The 5 -year overall survival rate tended to be higher in the SPS group than in the MPS group $(77.5 \%$ in the SPS group $v s .60 .9 \%$ in the MPS group, $p=0.126$ ). However, the 5-year cancer-specific survival rate did not differ significantly between groups $(89.6 \%$ in the SPS group $v s .82 .7 \%$ in the MPS group, $p=0.405$ ). She et al. reported that the 5-year overall survival rate and the 5year disease-specific survival rate was $52.8 \%$ and $68.9 \%$, respectively (27). Otsuka et al. reported that the 5-year overall survival rate and the 5-year disease-specific survival rate was $64.8 \%$ and $91 \%$, respectively (28). Our results indicated that SPS can provide short-term oncological outcomes comparable to those of MPS in octogenarians with colon cancer.

The main limitations of this study were that it was carried out at a single institution, it had a small sample size, it was retrospective in nature, and it seemed to be biased toward the surgical approach. In addition, our total patient population may be typical for Japan, but may not be applicable to the average European or United States population. It is difficult to demonstrate the true clinical significance of differences between SPS and MPS in octogenarians with colon cancer in this study. However, it seems that SPS has no adverse effects on clinical outcomes in octogenarians with colon cancer.

\section{Conclusion}

This is the first report describing that SPS can provide clinical outcomes comparable to those of MPS in elderly patients with colon cancer. More studies of SPS and large,

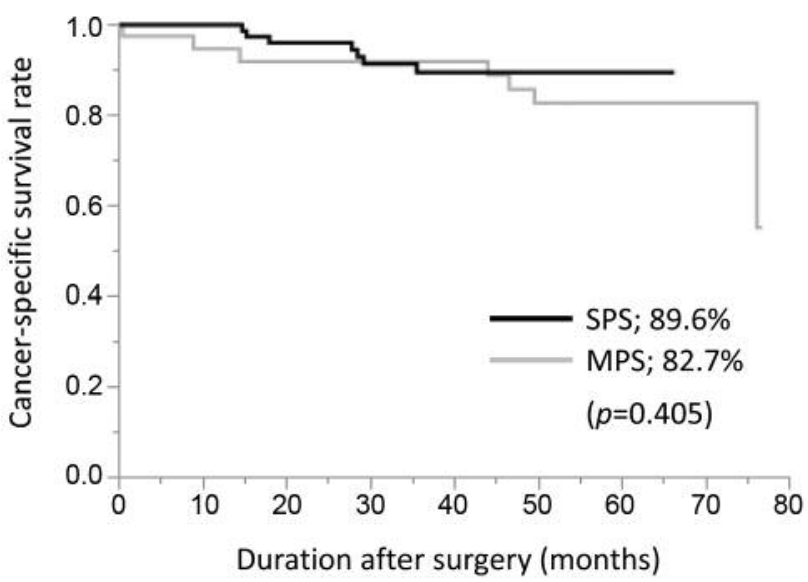

Figure 4. Kaplan-Meier analysis of cancer-specific survival at 5 years in the SPS and MPS group.

prospective randomized trials are needed to validate the benefits of SPS, including both short- and long-term oncological outcomes compared to MPS in elderly patients with colon cancer.

\section{References}

1 Vignali A, Di Palo S, Tamburini A, Radaelli G, Orsenigo E and Staudacher C: Laparoscopic vs. open colectomies in octogenarians: a case-matched control study. Dis Colon Rectum 48: 2070-2075, 2005.

2 Sklow B, Read T, Birnbaum E, Fry R and Fleshman J: Age and type of procedure influence the choice of patients for laparoscopic colectomy. Surg Endosc 17: 923-929, 2003.

3 Yamamoto S, Watanabe M, Hasegawa H, Baba H and Kitajima M: Short-term outcomes of laparoscopic colonic surgery in octogenarians: a matched case-control study. Surg Laparosc Endosc Percutan Tech 13: 95-100, 2003.

4 Senagore AJ, Madbouly KM, Fazio VW, Duepree HJ, Brady KM and Delaney CP: Advantages of laparoscopic colectomy in older patients. Arch Surg 138: 252-256, 2003.

5 Law WL, Chu KW, and Ming Tung PH. Laparoscopic colorectal resection: a safe option for elderly patients. J Am Coll Surg 195: 768-773, 2002.

6 Delgado S, Lacy AM, García Valdecasas JC, Balaque C, Salvador L, Momblan D and Visa J: Could age be an indication for laparoscopic colectomy in colorectal cancer? Surg Endosc 14: 2226, 2000.

7 Stocchi L, Nelson H, Young-Fadok TM, Larson DR and Ilstrup DM: Safety and advantages of laparoscopic vs. open colectomy in the elderly: matched-control study. Dis Colon Rectum 43: 326-332, 2000.

8 Hinoi T, Kawaguchi Y, Hattori M, Okajima M, Ohdan H, Yamamoto S, Hasegawa H, Horie H, Murata K, Yamaguchi S, Sugihara K and Watanabe M; Japan Society of Laparoscopic Colorectal Surgery: Laparoscopic versus open surgery for colorectal cancer in elderly patients: a multicenter matched casecontrol study. Ann Surg Oncol 22: 2040-2050, 2015. 
9 Japan Society for Endoscopic Surgery: Survey of endoscopic surgery in Japan. J Jpn Soc Endosc Surg 17: 571-679, 2012.

10 Remzi FH, Kirat HT, Kaouk JH and Gersier DP: Single-port laparoscopy in colorectal surgery. Colorectal Dis 10: $823-826$, 2008.

11 Papaconstantinou HT and Thomas JS: Single-incision laparoscopic colectomy for cancer: assessment of oncologic resection and shortterm outcomes in a case-matched comparison with standard laparoscopy. Surgery 150: 820-827, 2011.

12 Champagne BJ, Papaconstantinou HT, Parmar SS, Nagle DA, Young-Fadok TM, Lee EC and Delaney CP: Single-incision versus standard multiport laparoscopic colectomy: a multicenter, case-controlled comparison. Ann Surg 255: 66-69, 2012.

13 Poon JT, Cheung CW, Fan JK, Lo OS and Law WL: Singleincision versus conventional laparoscopic colectomy for colonic neoplasm: a randomized, controlled trial. Surg Endosc 26: 27292734, 2012.

14 Chen WT, Chang SC, Chiang HC, Lo WY, Jeng LB, Wu C and Ke TW: Single-incision laparoscopic versus conventional laparoscopic right hemicolectomy: a comparison of short-term surgical results. Surg Endosc 25: 1887-1892, 2011.

15 Takemasa I, Uemura M, Nishimura J, Mizushima T, Yamamoto H, Ikeda M, Sekimoto M, Doki Y and Mori M: Feasibility of single-site laparoscopic colectomy with complete mesocolic excision for colon cancer: a prospective case-control comparison. Surg Endosc 28: 1110-1118, 2014.

16 Yun JA, Yun SH, Park YA, Cho YB, Kim HC, Lee WY and Chun HK: Single-incision laparoscopic right colectomy compared with conventional laparoscopy for malignancy: assessment of perioperative and short-term oncologic outcomes. Surg Endosc 27: 2122-2130, 2013.

17 Katsuno G, Fukunaga M, Nagakari K, Yoshikawa S, Azuma D and Kohama S: Short-term and long-term outcomes of singleincision versus multi-incision laparoscopic resection for colorectal cancer: a propensity-score-matched analysis of 214 cases. Surg Endosc 30: 1317-1325, 2016.

18 Tei M, Wakasugi $\mathbf{M}$ and Akamatsu $\mathrm{H}$ : Comparison of the perioperative and short-term oncological outcome after singleor multi-port surgery for colorectal cancer. Colorectal Dis 17: O141-O147, 2015.

19 Charlson ME, Pompei P, Ales KL and MacKenzie CR: A new method of classifying prognostic comorbidity in longitudinal studies: development and validation. J Chronic Dis 40: 373-383, 1987.
20 Japanese Classification of Colorectal Carcinoma: Japanese Research Society for Cancer of the Colon and Rectum. 2nd English ed. Tokyo, Kanehara Shuppan, 2009.

21 Dindo D, Demartines N and Clavien PA: Classification of surgical complications: a new proposal with evaluation in a cohort of 6336 patients and results of a survey. Ann Surg 240: 205-213, 2004.

22 Tei M, Wakasugi M and Akamatsu H: Comparison of short-term surgical results of single-port and multi-port laparoscopic rectal resection for rectal cancer. Am J Surg 210: 309-314, 2015.

23 Tei M, Wakasugi M, Kishi K, Tanemura M and Akamatsu H: Incidence and risk factors of postoperative delirium in elderly patients who underwent laparoscopic surgery for colorectal cancer. Int J Colorectal Dis 31: 67-73, 2016.

24 Al-Refaie WB, Parsons HM, Habermann EB, Kwaan M, Spencer MP, Henderson WG and Rothenberger DA: Operative outcomes beyond 30-day mortality: colorectal cancer surgery in oldest old. Ann Surg 253: 947-952, 2011.

25 Koh FH, Wong J, Tan JK, Tan KK, Cheong WK and Lieske B: Laparoscopic colorectal surgery is safe and benefits octogenarian patients with malignant disease: a matched case-control study comparing laparoscopic and open colorectal surgery. Int $\mathrm{J}$ Colorectal Dis 30: 963-968, 2015.

26 Issa N, Grassi C, Melki Y, Powsner E and Dreznik Z: Laparoscopic colectomy for carcinoma of the colon in octogenarians. J Gastrointest Surg 15: 2011-2015, 2011.

27 She WH, Poon JT, Fan JK, Ko OS and Law WL: Outcome of laparoscopic colectomy for cancer in elderly patients. Surg Endosc 27: 308-312, 2013.

28 Otsuka K, Kimura T, Hakozaki M, Yaegashi M, Matsuo T, Fujii $\mathrm{H}$, Sato K, Hatanaka T and Sasaki A: Comparative benefits of laparoscopic surgery for colorectal cancer in octogenarians: a case-matched comparison of short- and long-term outcomes with middle-aged patients. Surg Today 47(5): 587-594, 2017. 